\title{
Intelligence, Age and Schooling: Data from the Battery of Reasoning Tests (BRT-5)
}

\author{
Inteligência, Idade e Escolarização: Dados da Bateria \\ de Provas de Raciocínio (BPR-5)
}

\author{
Ricardo Primi ${ }^{*}, a$, Gleiber Couto ${ }^{b}$, Leandro S. Almeida ${ }^{c}$, M. Adelina Guisande ${ }^{d}$ \\ \& Fabiano Koich Miguel $^{e}$ \\ ${ }^{a}$ Universidade São Francisco, Itatiba, Brasil, ${ }^{b}$ Universidade Federal de Goiás, Catalão, Brasil, \\ 'Universidade do Minho, Braga, Portugal, \\ ${ }^{d}$ Universidade de Santiago de Compostela, Santiago de Compostela, España \\ $\&{ }^{e}$ Universidade Estadual de Londrina, Londrina, Brasil
}

\begin{abstract}
Intelligence is commonly divided into two distinctive areas: fluid intelligence (Gf), which is understood as the skill of reasoning or intelligence as a process, and crystallized intelligence (Gc) that involves skills that are more related to learning and experience (knowledge-based skills). The objective of the present work was to investigate the effects that schooling and age exert on fluid and crystallized intelligence measuring students' results in sub-tests of the Battery of Reasoning Test (BRT-5). This study considered a sample composed of 1,722 students - 603 were assessed with Form A of the battery and 1,119 with Form B. The results show that intelligence is systematically associated with schooling and age. Some difficulties in separating the effects of cognitive development from the effects of formal learning on students' cognitive performance are also emphasized.

Keywords: Intelligence, fluid/crystallized intelligence, psychometrics, schooling, age.

Resumo

A inteligência é comumente dividida em fluida (Gf), entendida como habilidade de raciocínio ou inteligência como um processo, e cristalizada $(\mathrm{Gc})$ como as habilidades mais associadas à aprendizagem e experiência (habilidades associadas aos conhecimentos). No presente trabalho, o objetivo foi investigar os efeitos que a escolarização e a idade exercem sobre Gf e Gc tomando os resultados dos alunos nos subtestes da Bateria de Provas de Raciocínio (BPR-5). Este estudo considerou uma amostra composta por 1722 estudantes respondendo 603 à forma A dessa bateria e 1119 à sua forma B. Os resultados apontam relações sistemáticas entre inteligência, escolaridade e idade. Também se enfatiza a dificuldade em se separar os efeitos do desenvolvimento cognitivo e da aprendizagem formal no desempenho cognitivo dos alunos.

Palavras-chave: Inteligência, inteligência fluida/cristalizada, psicometria, escolarização, idade.
\end{abstract}

Even though there is some controversy concerning the definition and measurement of intelligence, a relative consensus on the Cattell-Horn-Carroll hierarchical model of cognitive abilities has been noted in the last decade (McGrew, 1997, 2005). As its name suggests, this model incorporates the Gf-Gc theory, which initially originated with the work of Raymond Cattell $(1963,1971)$ and which later on was developed and extended by Horn and Cattell (1966) in articulation with the model proposed by Carroll (1993) based on a massive meta-analysis work.

\footnotetext{
" Endereço para correspondência: Departamento de Psicologia, Universidade São Francisco, Rua Alexandre Rodrigues Barbosa, 45, Itatiba, SP, Brasil 13251-900. Email: rprimi@mac.com.br, gleibercouto@yahoo.com.br, leandro@ie.uminho.pt, mariaadelina.guisande@usc.es e fabiano@labape.com.br.

Agência de financiamento CNPq.
}

The psychometric theory of Cattell (Gf-Gc) initially proposed a detailed elaboration of the $g$ factor concept of Spearman (1927) into two components: fluid intelligence, $G f$, and crystallized intelligence, $G c$. On one hand, $G f$ is understood as the potential for understanding and relating information, as well as solving new problems for which there is no available knowledge previously stored in memory. Thus, it implies deliberate implementation and controlled and systematic mental processes in order to find relationships between information organisation (induction) and the derivation of information (deduction). On the other hand, $G c$ is understood as the quality - in terms of its breadth and depth - of knowledge gained from the process of acculturation, which occurs through formal schooling and life experiences. This way, the information base $(G c)$ makes it easier to understand 
information and solve problems that are repeated in lives of people in a relatively automatic way using the application of information already known.

Although postulated as two relatively distinct abilities, these factors are highly related, because the investment of fluid intelligence in the learning experience promotes the development and structuring of knowledge and skills in specific areas that lead to crystallized intelligence. Hence, these capabilities might be highly correlated, since high investment of $G f$ in learning will result in success in various areas of knowledge that leads to a correlation with $G c$. On the other hand, besides being influenced by $G f, G c$ is also relatively more vulnerable to cultural resources promoting learning (such as the access and quality of formal and informal educational interventions) and other individual variables such as motivation, interest and dedication. Thus, people with similar levels of $G f$ but distinct socio-cultural backgrounds will differ in $G c$, resulting in a relative separation of $G f$. In short, $G f$ can be understood as a more "pure" general capacity that is closer to brain maturation; a more "fluid" one, as the name denotes, which metaphorically refers to the idea of something that is not yet fully complete. On the contrary and despite its historical roots in $G f, G c$ reflects the sum of influences of the experiences of an individual. In this way, the "crystallized" $G f$ potential is molded by the application of $G f$ in varied learning experiences (Johnson \& Bouchard, 2005; Kvist \& Gustafsson, 2008). In a more recent version of that theory, seven other abilities were added besides $G f$ and Gc (Carroll, 1993; Horn, 1991; Horn \& Noll, 1997).

At the same time that the $G f-G c$ model was evolving, Carroll (1993) completed his seminal meta-analytical scanning work about 60 years of investigations on intelligence and the re-analysis of 461 data sets from 1500 references, which included almost all major and classical psychometric studies. This study resulted in a three-tier hierarchical model of intelligence. Despite the differences between the models of Carroll and Cattell and Horn, the gathering of these three authors as technical advisers for the Woodcock WJ-R test (McGrew, 2009) led to the creation of an "umbrella" terminology integrating these theories, which has since been known as the Cattell-HornCarroll (CHC) theory of cognitive abilities (Carroll, 1997; Flanagan, Genshaft, \& Harrison, 1997; Horn \& Noll, 1997; McGrew \& Flanagan, 1998). Some studies have referred to the CHC model as the most consensual, complete and modern description of intelligence (Flanagan \& Ortiz, 2001; McGrew, 1999; McGrew \& Flanagan, 1998; Phelps, McGrew, Knopik, \& Ford, 2005; Primi \& Almeida, 2002; Stankov, 2000a, 2000b). Such contributions lead the research in the area especially that aimed at understanding the factors measured by intelligence tests.

One central question concerning intelligence research refers to the degree to which the educational system exerts an impact in the development of cognitive abilities. The origin of the primary concepts of the $G f-G c$ theory has to do with this problem, since they were originally presented at a symposium back in the 1940s, which focused on the influence of age on cognitive abilities. Two classes of influences on cognitive development were proposed at the symposium: educational and cultural opportunities and neurological maturational, which are obviously associated to $G c$ and $G f$, respectively (Horn, 1991).

These concepts were adopted by Ackerman (1996), who proposed a theory about the cognitive development of adults. This model refers to intelligence as a process and intelligence as knowledge. Once again the difference is between the ability of deductive and inductive reasoning on the one hand and knowledge and skills on the other. In the latter case, one is facing cognitive abilities, whose development and expression in many fields, are the result of a long line of studies, experiences and deliberate practices and whose development is expressed through structures of expertise. For this reason, according to Ackerman (1996), the two types of intelligence differ in their development.

In terms of its development, $G f$ has its peak at the end of adolescence and early adulthood. Thereafter, it remains stable for a few years until it starts to decline, especially in aspects related to processing speed, while on the contrary $G c$ is developed in a slow and gradual way. This way, $G f$ stabilizes at the end of the early years of adulthood and remains so for a longer period than $G c$, which begins its decline at a relatively advanced (elderly) stage. As an example, see the analysis of McGrew and Evans (2002) concerning the sub-tests of Woodcock Johnson III (WJIII). These differential patterns about the influence of the age and schooling variables on cognitive abilities have served as evidence of the validity of the approach that presents the $G f$ and $G c$ constructs as being relatively distinct, although highly correlated.

Therefore, several studies seem to emphasize a differential impact of education on different cognitive abilities (Almeida, 1988; Cattell, 1971; Gustafsson, 2001; McGrew \& Evans, 2002). In order to differentiate the impact of schooling and age (development related to maturation), the results suggest that education has an important contribution for performance in testing situations, including those more related to fluid intelligence. Thus, there is some convergence of research, which suggests that fluid intelligence is influenced by education, even if this influence is less solid compared to that which occurred in tests related to crystallized intelligence (Cahan \& Noyman, 2001; Stelzl, Merz, Eulers, \& Remer, 1995).

A major methodological problem inherent in these studies concerns the separation of the influence of school in cognitive development regardless of maturational development (Ceci, 1991; Cliffordson \& Gustafsson, 2008; Stelzl et al., 1995). In regard to children, it is frequently assumed that the age variable is an indicator of neural maturation and that years of study are an indicator of education and the consequential impact of formal schooling. However, there is a high correlation between age and schooling: age, especially in childhood, follows maturational develop- 
ment and, therefore, the association between it and cognitive abilities is taken as an estimation of the influence of biological factors in the development of intelligence. Schooling is a variable associated with formal stimulation and, therefore, its association with intelligence is taken to estimate the influence of environmental factors in the school context. Still, since age increase follows education increase, it is difficult to separate the unique influence of one and the other on cognitive development.

It is more plausible to conceive that maturational cognitive development, due to organic growth, is accompanied by systematic stimulation that occurs in school, so that the two factors operate together and influence cognitive development in an interactive way. Even so, when analyzing the association of these variables alone (age and education) with intelligence, there is a considerable amount of shared variance and this association cannot be easily justified as attributable to education or age but rather by both factors simultaneously.

A methodological strategy adopted to try to separate the influence of these variables is based on the fact that:

children of 1 year of chronological age with the effect of schooling held constant can be estimated from the difference between the youngest and oldest child within the same grade level. On the other hand, the effect of 1 year of school attendance with chronological age held constant can be estimated from the difference between the oldest child of any given grade level and the youngest child of following one. (Stelzl et al., 1995, p. 281)

Such methodology makes it possible to use a small unique portion of variability of one variable that exists within constant levels of the other, thus allowing the estimation of the specific effect of each. Cliffordson and Gustafsson (2008), as well as Stelzl et al. (1995), used this methodology and noted that schooling has a greater effect than age in cognitive development, which is consistent with the data reviewed by Ceci (1991). There is also evidence that the change is greater in tests where content resembles the domain of school syllabuses. Also - in samples of young adults - age has a negative effect on fluid intelligence tests, which is consistent with the decline of $G f$, despite occurring at earlier ages than traditionally observed.

In short, the literature reviewed shows evidence of the existence of differential patterns of association between age/education with $G c$ and $G f$. These patterns can be used as a reference for studies of test validation that are proposed to measure such constructs. The present study proposes to investigate the associations of schooling and age with scores on five sub-tests of the Battery of Reasoning Tests (BRT-5; Primi \& Almeida, 1998). Psychometric studies of BRT-5 use traditional intra group norms, when comparing students with the same level of schooling. More recently, a study was developed using the Item Response Theory to equate scores of Forms A and B (Couto, 2005, 2007). Using a common scale for
Forms A and B, it was possible to compare the scores of all school levels covered by BRT-5. This article is, therefore, aimed at studying the relationship between schooling and age, as well as the equated scores of the BRT- 5 , as an additional study of validity of the battery sub-tests. The main issue investigated was whether the variable school/ age had a different association for different sub-tests due to the composition hypothesized for these sub-tests.

\section{Method}

\section{Sample}

The data resulted from the Brazilian standardization study of BRT-5. From the sample of 1,722 students, 603 answered Form A of the test. $30.4 \%$ of the students were enrolled in the sixth grade (183), $29.3 \%$ in the seventh grade (175) and $40.3 \%$ in the eighth grade (245). Students were aged between 11 and 18 years old. $48.9 \%$ were male (295) and 51.1\% female (308). The remaining 1,119 students answered Form B. $25.2 \%$ of these students were in their freshmen year of high school (282), $52.1 \%$ in their second year (583) and $22.7 \%$ in their third year (254). Students were aged between 14 and 21 years old with $42.7 \%$ being male (478) and $57.3 \%$ female (641). It is important to clarify that the educational system in Brazil is divided into three cycles: elementary school, which ranges from first to eighth grade, high school, which ranges from ninth to eleventh grade and, finally, superior education, where the number of years depends on the chosen course (Psychology, Law, Engineering, Computing, etc.). Each school year is called a "grade," so the text referring to tenth grade, for example, is to be understood as the second grade of high school and so on in respect to the other years of elementary and high school. The Brazilian standardization study occurred during 1998 and 1999, when the two forms were applied to students from elementary and middle schools in different cities in the states of São Paulo (Santo André, São Bernardo, Campinas, Itatiba, Morungaba and Mogi Guaçú) and Rio Grande do Sul (São Leopoldo and Novo Hamburgo).

\section{Instrument}

The BRT-5 (Primi \& Almeida, 1998) was developed from the Differential Reasoning Tests Battery (BPRD; Almeida, 1988). It is composed of five sub-tests: Abstract Reasoning (AR) consisting of 25 items involving analogies with geometrical figures that have to be answered within a twelve minute time limit; Verbal Reasoning (VR) consisting of 25 items involving analogies between words that have to be answered in a ten minute time limit; $\mathrm{Nu}$ merical Reasoning (NR) consisting of 20 items in which linear or alternating series of numbers are presented and the student must find the rules of arithmetical progression for each series in order to find the two numbers that complete the sequence within an eighteen minute time limit; Spatial Reasoning (SR) consisting of 20 items that present sets of three-dimensional cubes in motion for the student 
to find the type of motion from an analysis of different faces and then choose the answer that represents the last cube in the series, which also has to be answered in an eighteen minute time limit; and Mechanical Reasoning (MR), which is composed of 25 items containing pictures of the practical contents of physics and mechanics from which the student must choose the answer that best represents the outcome of every situation, which has to be answered in a fifteen minute time limit.

In Brazil there are two available forms: Form A for students ranging in the sixth to eighth grades of elementary school and Form B for students ranging from the first to third grades of high school. There is an ongoing study aiming at a first version for the first to fifth grades (Cruz, 2008). In Portugal the battery is available in three forms according to the schooling of the students. They are for the fifth and sixth grades, the seventh to ninth grades and for the tenth to twelfth grades. The forms are equivalent, have been validated in the same way in the two countries and show adequate indices of reliability and validity (see Primi \& Almeida, 2000 for details).

The BRT-5 has its theoretical roots in psychometric models and in cognitive psychology (Primi \& Almeida, 1998). Its series, analogies and problem solving items (practical situations involving mechanical objects) describe a measure of inductive reasoning and - through this - the broad $G f$ factor. As reported in the literature, there is strong evidence that $G f$ matches the $g$ factor. Therefore, according to this perspective, the general score of BRT-5 is supposed to reflect the $g$ factor (Kvist \& Gustafsson, 2008). The original intention of the BRT-5 was to obtain a measure of $g$ by means of the sum of five sub-tests with different content but it settled on the same task of analogical inductive reasoning with $g$ as the main factor. At the same time, every sub-test was designed to provide information about specific factors associated with the content of tasks; namely, $G c$ in the VR and NR sub-tests or $G v$ (visuo-spatial intelligence) in the SR and AR sub-tests.

A number of empirical studies support these interpretations. For example, Primi and Almeida (2000) found a one-dimensional solution explaining most of the covariance between sub-tests of the BRT-5. Cruz (2008), in a joint factor analysis of the BRT- 5 sub-tests with tests of reading, academic classifications and Raven Progressive Matrices, clearly found two $G f$ and $G c$ factors, and that Raven was grouped with the sub-tests of the BRT-5 in the $G f$ factor. In a correlation analysis of BRT5-6 with the WISC-IV sub-tests, Almeida et al. (2007) found that the VR correlates with greater magnitude in Similarities and Comprehension sub-tests, the Cubes with $\mathrm{AR}$ and the NR with the Arithmetic, Cubes and Information sub-tests. This data is consistent with the hypothesis that these correlations are relatively high because of specific factors $G c, G v$ (visuo-spatial intelligence) and $G q$ (quantative intelligence). In terms of predicting school grades, generally there are larger magnitudes of VR and NR tests with Portuguese and Mathematics, respectively and of AR with
Mathematics grades (Almeida et al., 2007; Cruz, 2008; Lemos, Almeida, Guisande, \& Primi, 2008; Primi \& Almeida, 2000). Finally, Primi and Almeida (1998) noted that, in Portugal, students of natural sciences and arts have higher scores on AR, SR and MR tests, whereas students in the humanities area present lower scores. These differences are not significant with respect to VR but these results are consistent with the hypothesis that these tests measure a specific $G v$ component, which would explain the higher results of students in the tests with content more related to their academic curriculum.

\section{Procedures}

BRT-5 sub-tests of Forms A and B were equated using the common item method. A single database of all subjects and their responses to Forms A and B was then prepared, which assumed that the missing responses were unique to each form. The Rasch model was applied five times once for each sub-test (AR, VR, NR, SR and MR) - in order to calibrate items and estimate measures for the subjects (Couto, 2005, 2007). Subject theta values on Logit scale were linearly transformed into traditional IQ scale $(M=100 ; S D=15)$ using the average calculated for the third grade of high school, as a reference and the standard deviation calculated for the total sample. The average of this sub-group was chosen, because the literature indicates that fluid intelligence tends to have its peak around this age group. Thus, the choice of this reference point describes the value 100 as the average fluid intelligence peak in relation to the age of the groups involved. The choice of the Logit standard deviation from the total sample was made in order to try to obtain a more reliable estimate of the dispersion of the scores that could logically be obtained from a larger sample instead of a sub-set of the sample.

As discussed previously, when studying the associations of age and education with cognitive measures, there is always the problem of multi-collinearity between the first two variables (in this study the correlation between age and grade is $r=87$ ). Since schooling development goes along with age, it is difficult to separate the single association that each variable has on intelligence. In trying to extract the maximum amount of information from the two variables - education and age - a series of systematic regression analyses was used, as explained below.

Conceiving schooling as age accompanied by education, this variable was always entered as the first variable in the regressions that had BRT-5 sub-tests as dependent variables. Its effect is interpreted as indicating the simultaneous effect of age accompanied by progressive formal schooling. A second predictor - called the residual age (rAge) - was obtained from a regression having age as the dependent variable and schooling as an independent variable, which represents age variation that could not be predicted by schooling. Generally speaking, this predictor indicates age-grade distortion, where students that were retained in a grade due to insufficient school achievement 
would score higher. Conversely, younger students who are in a grade consistent with their age would score lower. Therefore, this variable was included in the regression analysis after age and may be interpreted as age unaccompanied by schooling.

It must be stressed that this methodology does not isolate the unique effects of each variable, because the first one (schooling) carries the effect of age accompanied by schooling. Thus, the first effect contains age intertwined with schooling. However, the second variable (residual age) brings a unique variance associated with increase in age that is not explained by schooling. Together these two variables add up to the maximum information contained in both variables. The logic of using the age residual and not a school residual is based on the fact that it is possible to observe increase in age unaccompanied by schooling and its variance would be higher the more pronounced are cases with age-grade distortion in the sample. On the other hand, it is not possible to observe an increase in school unaccompanied by age increase, because the latter is uninterrupted.
A Repeated Measures Analysis of Variance (ANOVA) was initially employed with normalized sub-test theta scores as dependent variables, the type of sub-test (5) as an intra-subject variable, school grades (SG) and the administrative dependence (AD) of the school to which it belonged (public and private) as between group variables. The variable AD was included, because in all normative studies of BRT-5 the type of educational establishment has always been strongly associated with performance. In Brazil, there is a very large socio-economic gap between the populations of the two educational establishments. Therefore, this variable ended up being an indicator of the social, economic and cultural environment of the students, although an indirect one. One can interpret this variable as an indirect indicator of the wealth of resources that allows the creation of a positive environment for learning and intellectual development. Finally, five multiple regression analyses were run using the stepwise method in which the BRT-5 normalized subtests were defined as dependent variables with SG and rAge being independent variables.

Table 1

Descriptive Statistics of Standardized and Equated Scores on BRT-5 Sub-tests according to Sub-tests, Grade and Administrative Dependency of the Schools

\begin{tabular}{|c|c|c|c|c|c|c|c|}
\hline Grade & Administration & & $\mathrm{AR}$ & VR & MR & SR & NR \\
\hline \multirow[t]{4}{*}{6} & Public & $M$ & 65.6 & 63.3 & 77.7 & 76.7 & 66.6 \\
\hline & & $S D$ & 16.9 & 13.8 & 9.8 & 12.0 & 16.4 \\
\hline & Private & $M$ & 83.0 & 80.4 & 85.6 & 87.3 & 84.4 \\
\hline & & $S D$ & 16.0 & 15.4 & 10.6 & 12.9 & 18.3 \\
\hline \multirow[t]{4}{*}{7} & Public & $M$ & 69.1 & 68.3 & 79.0 & 79.4 & 75.5 \\
\hline & & $S D$ & 17.0 & 12.7 & 11.7 & 9.8 & 13.2 \\
\hline & Private & $M$ & 85.2 & 83.0 & 85.9 & 90.6 & 84.6 \\
\hline & & $S D$ & 17.9 & 14.0 & 10.8 & 13.1 & 17.5 \\
\hline \multirow[t]{4}{*}{8} & Public & $M$ & 80.3 & 74.5 & 81.8 & 84.0 & 81.5 \\
\hline & & $S D$ & 16.5 & 15.1 & 12.7 & 11.9 & 18.5 \\
\hline & Private & $M$ & 89.8 & 87.0 & 91.4 & 95.6 & 92.7 \\
\hline & & $S D$ & 16.6 & 14.1 & 12.6 & 14.0 & 14.6 \\
\hline \multirow[t]{4}{*}{9} & Public & $M$ & 84.7 & 82.8 & 85.8 & 87.8 & 83.2 \\
\hline & & $S D$ & 16.0 & 13.2 & 13.0 & 12.0 & 13.6 \\
\hline & Private & $M$ & 94.8 & 91.2 & 96.2 & 98.3 & 90.0 \\
\hline & & $S D$ & 15.5 & 11.6 & 13.9 & 14.7 & 13.3 \\
\hline \multirow[t]{4}{*}{10} & Public & $M$ & 88.1 & 87.6 & 90.7 & 88.6 & 85.9 \\
\hline & & $S D$ & 14.3 & 12.7 & 13.1 & 13.1 & 14.9 \\
\hline & Private & $M$ & 94.0 & 94.0 & 95.6 & 94.2 & 91.8 \\
\hline & & $S D$ & 13.9 & 12.9 & 12.5 & 12.4 & 12.8 \\
\hline \multirow[t]{4}{*}{11} & Public & $M$ & 86.4 & 87.0 & 87.2 & 86.7 & 86.9 \\
\hline & & $S D$ & 13.8 & 14.5 & 13.3 & 10.4 & 14.6 \\
\hline & Private & $M$ & 105.3 & 104.4 & 106.2 & 104.6 & 103.0 \\
\hline & & $S D$ & 12.3 & 12.5 & 13.1 & 13.4 & 12.4 \\
\hline \multirow[t]{6}{*}{ Total } & Public & $M$ & 82.2 & 80.4 & 85.7 & 85.6 & 82.0 \\
\hline & & $S D$ & 17.2 & 15.8 & 13.5 & 12.7 & 16.2 \\
\hline & Private & $M$ & 94.3 & 92.9 & 95.7 & 96.3 & 93.1 \\
\hline & & $S D$ & 16.5 & 15.6 & 14.4 & 14.3 & 15.6 \\
\hline & Total & $M$ & 87.9 & 86.3 & 90.5 & 90.6 & 87.2 \\
\hline & & $S D$ & 17.9 & 16.8 & 14.8 & 14.5 & 16.9 \\
\hline
\end{tabular}


Table 2

Results for the Analysis of Variance of BRT-5 (5 sub-tests within subject) X School Grades (SG, 6 between groups) X Administrative Dependence (AD, two levels)

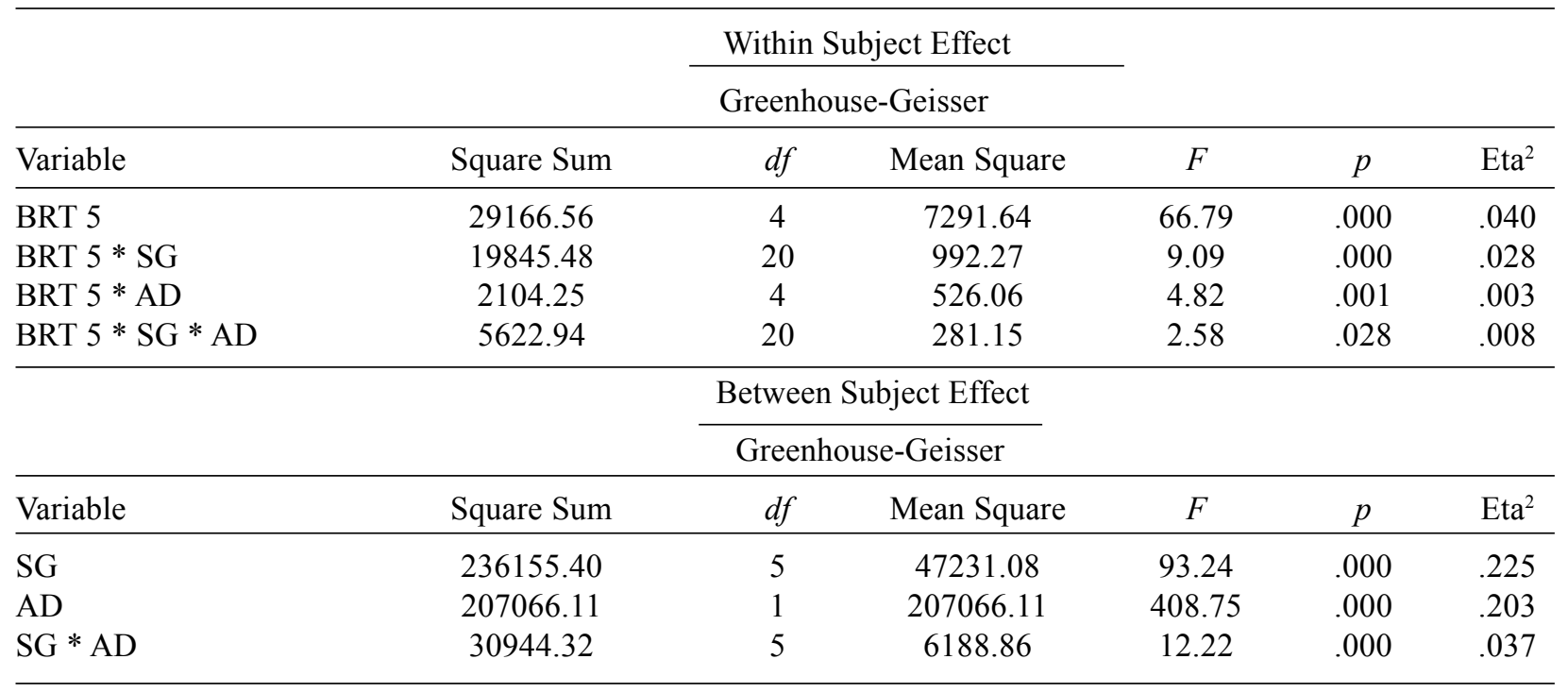

\section{Results}

Table 1 shows the mean and the standard deviations of the results of BRT-5 sub-tests by school grade and administrative dependency (public or private). Figure 1 plots the means against the same variables showing the patterns of the data. Table 2 presents the results of the ANOVA 5 (BRT-5) X 6 (grades) X 2 (administrative dependency) having the standardized score as a dependent variable, the type of sub-test as a within subject variable (BRT-5), and grade and administrative dependence as between factors.

All the main effects and interactions were significant but they differ in magnitude. The effect of greater theoretical importance is the variable grade, which in association with the type of school did indeed reveal greater magnitude, thus explaining $22 \%$ and $20 \%$ of the variance, respectively. In general, the scores increase with grades and the students from private schools generally have higher performances. There is also a significant interaction between these two variables. In general, as can be seen in Figure 1, for students from public schools (left panel) the increase occurs up to the eighth grade of elementary school. In high school, the increases are much smaller or non-existent. Amongst the students of private schools (right panel), one continues to observe an average increase with grade in high school. In this group of students, despite a drop between the first and second year for some sub-tests, there is a considerable increase of performance

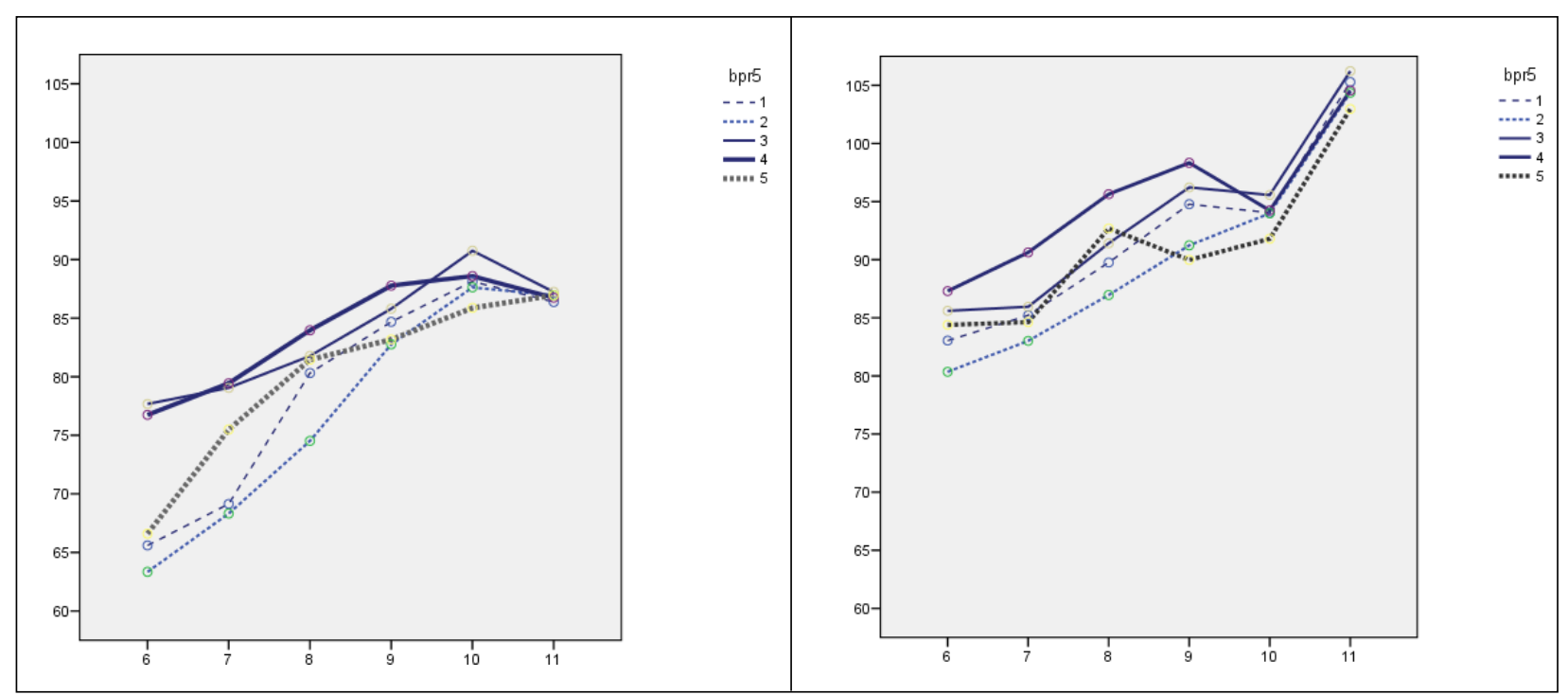

Figure 1. Average standardized scores in BRT-5 sub-tests (1:AR, 2:VR, 3:MR, 4:SR and 5:NR) for public (left panel) and private (right panel) schools. 
Primi, R., Couto, G., Almeida, L. S., Guisande, M. A. \& Miguel, F. K. (2012). Intelligence, Age and Schooling: Data from the Battery of Reasoning Tests (BRT-5).

from the second to the third year of high school. These effects interact with the BRT-5 tests, setting different standards depending upon the test. It is interesting to note that the rate of increase with grade varies depending upon the sub-test with VR displaying a pattern of steady increase over the series.

Table 3 shows the results of multiple regression analysis (using the stepwise procedure) in order to try to predict the standardized scores in each sub-test from the School Grade (SG) and the Residual Age (rAge). Data indicates that the grade is always a significant predictor in the model and with the greater magnitude. However, it must be recalled that this effect carries the effect of age; in other words, it is intertwined with the effect of age and, therefore, cannot be taken as indicative of the greater importance of grade over age.

Table 3

Results of Multiple Regression Modeling Test Performance from the School Grade (SG) and Residual Age (rAGE) for the Five Sub-tests

\begin{tabular}{lrrrr}
\hline Variables/Predictor variables & $B$ & EP & $\beta$ & $R, R^{2}, \Delta R^{2}$ and ANOVA \\
\hline AR & & & & \\
SG & 5.08 & .25 & $* * * 0.47$ & $R=.47 ; R^{2}=.22 ; \Delta R^{2}=.04$ \\
rAge & -3.49 & .38 & $* * *-0.19$ & $* * * F(1,1695)=246.18$ \\
VR & & & & \\
SG & 5.59 & .22 & $* * * 0.51$ & $R=.54 ; R^{2}=.29 ; \Delta R^{2}=.02$ \\
rAge & -2.70 & .33 & $* * *-0.16$ & $* * * F(1,1694)=347.09$ \\
MR & & & & \\
SG & 3.91 & .21 & $* * * 0.42$ & $R=.42 ; R^{2}=.17 ; \Delta R^{2}=.00$ \\
rAge & -0.54 & .31 & $* *-0.04$ & $* * * F(2,1696)=178.83$ \\
SR & & & & \\
SG & 3.06 & .21 & $* * * 0.33$ & $R=.37 ; R^{2}=.13 ; \Delta R^{2}=.02$ \\
rAge & -2.32 & .33 & $* * *-0.16$ & $* * * F(1,1687)=130.67$ \\
NR & & & & \\
SG & 3.78 & .24 & $* * * 0.35$ & $R=.41 ; R^{2}=.17 ; \Delta R^{2}=.05$ \\
rAge & -3.69 & .37 & $* * *-0.22$ & $* * * F(1,1647)=169.36$ \\
\hline
\end{tabular}

$* * * p<.001 ; * * p<.10$

Residual age, on the other hand, has a significant effect of smaller magnitude and in the opposite direction, that is, the greater its value the lower the performance. To interpret this it must be remembered, due to the procedure that was used to calculate it, that it shows zero correlation with age. It indicates the distortions between school grade and age, that is, it is an indicator of the time that has been passed without the corresponding school progression. Thus, this effect indicates that the older students in the same grade tend to have a lower performance in the tests.

Some peculiarities are striking when analyzing the effects of these variables in the different sub-tests of BRT5 . The school grades have higher explanatory power in the VR test $(r=.51)$ and less explanatory power in the SR test. The residual age has increased its explanatory power in the NR test $\left(r=-.22 ; \Delta R^{2}=.05\right)$ followed by the AR test $\left(r=-.19 ; \Delta R^{2}=.04\right)$.

\section{Discussion and Conclusions}

This study was aimed at examining the relationship between schooling and age with the BRT- 5 sub-tests by exploring the patterns of association and their consistency with constructs that each sub-test is supposed to measure. In general terms, a systematic increase in performance scores was observed throughout the grades. This increase is slightly different depending on the type of school. In the group of students from private schools, where it can be generally inferred that the quality of education is due to higher financial resources, there is a relatively more linear increase throughout the years of schooling. This is more noticeable in the VR test and less in the SR and NR tests. In the group of students from public schools, where lower availability of resources can be inferred, there is a non-linear increase, which is higher in the first series but decreases in high school. Once again, this 
pattern is less prominent in the NR and more significant in the SR test.

Although it was not part of the goal of this study to test the effect of the type of school, this variable stood out as a prominent effect. The results were similar to what has been observed in studies that investigate the association of intelligence and/or achievement with socio-economic status (Braun, Jenkins, \& Grigg, 2006; Sirin, 2005). The type of school is conceptually closer to education than is age, since it indicates students of the same age but who attended different kinds of schools. This variance might mean differences concerning affluent neighborhoods, level of parental education, resources, extra-curricular activities and so on. This difference may be interpreted as an external variable indicating more informal education provided by parents of a higher educational level, as well as environments with more resources. The relative magnitude of the type of school was comparable as the effect of school grade. Therefore, it is an important variable deserving further systematic studies that should address the question of why it is so strongly associated with intelligence.

The increase observed in the scores seems to represent the influence of the combination of increased education with the development of the basic cognitive processes independent of learning (mostly age related) that are accompanied by the stimulus of schooling. According to the studies of Ackerman (1996) and McGrew and Evans (2002), the expected results for tests that are more related to $G f$ and $G v$, namely AR and SR, would be to the observance of a steady increase for the initial grades and a more modest growth in high school. For tests more related to $G c$, namely VR and NR, one would expect to see continuous growth, even for high school students. It was observed that the SR and VR sub-tests present a pattern that is closer to what one would expect, thus corroborating that the specific component of the VR test probably contains more $G c$ and the SR test more $G v$. In relation to the NR test - for which a pattern consistent with $G c$ was expected - it actually showed a pattern more consistent with $G f$. In contrast, the AR test appeared to be relatively more consistent with $G c$, especially when considering students in private school.

Regarding the NR test, although it involves mathematics content that is required to be learned at the most basic level in school (knowledge of arithmetical operations of addition, subtraction, multiplication and division), it can be inferred that this content is not complex enough to be a specific factor ( $G c$ or $G q$ ) of individual differences in samples of subjects in middle education, as is the case of the studied sample. So one can explain that in this sample there is a prevalence of reasoning components associated with $G f$ in the numerical series presented in the NR test.

In relation to the AR test, the results are more difficult to interpret. Although a decrease of the increase in scores in the final grades was expected, since $G f$ is relatively less easily influenced by schooling, the literature indicates that this influence exists (Cahan \& Noyman, 2001; Ceci, 1991; Cliffordson \& Gustafsson, 2008; Stelzl et al., 1995). within addition to this is the fact that a non-expected pattern was observed in the group of students in private schools, where both higher rates of developmental trajectories and also a higher quality of environmental stimulation - both formal (schools) and non-formal (family, friends) - was expected. So in this group it is possible to observe a continuing increase in all sub-tests.

Considering that the increase observed in the scores of all tests is the combined effect of cognitive development and education and that these two effects are combined in the grade and age variables, an attempt to estimate the effect of these two variables was made by optimizing the whole of the information contained therein. The results indicated that the increase in grades (carrying the impact of age) is associated with the increase in scores and the residual age is associated with a decrease of the scores. This data can be interpreted in two ways. On the one hand, if intelligence is thought to be a causal variable of achievement, these results could be interpreted as low intelligence being associated with low achievement and grade retention. In fact, the residual age is significantly correlated with the number of grade retentions, $r=.48, p<.001$. On the other hand, considering the idea of $G f$, as a consequential variable, this data may mean that the progression of intelligence is dependent on the advancement of schooling, although it may be a slow and indirect product of these factors. Because of the correlational nature of the data, it is not possible to decide in favor of one or other explanation but they can be considered as possible interpretations and both may be valid to some extent.

However, the methodology adopted in this study is attractive, because differential patterns may favor one or another hypothesis. If a test heavily influenced by school is considered, grade and residual effects of a high magnitude and an opposite direction should be observed, since school progression positively influences the development, while stagnation (an increase of age without following the progression of school) is a negative influence. Considering tests largely influenced by development and little influenced by schooling, a relatively lower grade effect should be observed, and it's magnitude would depend on how the variable is indicating age progression and the residual effect with positive direction.

Regarding the specificity of the sub-tests, the regression results also support the interpretation that VR has a more specific factor associated with $G c$, as it had the greater magnitude of the grade effect. In the remaining tests, the grade effect is relatively lower and similarly indicates a lower presence of $G c$.

In conclusion, the results are compatible with the ones found in literature in the field (Ackerman, 1996; Cahan \& Cohen, 1989; Cahan \& Noyman, 2001; Ceci, 1991; 
Primi, R., Couto, G., Almeida, L. S., Guisande, M. A. \& Miguel, F. K. (2012). Intelligence, Age and Schooling: Data from the Battery of Reasoning Tests (BRT-5).

Gustafsson, 2001; McGrew \& Evans 2002; Stelzl et al., 1995), thus corroborating in part the interpretations of the specific factors involved in the BRT- 5 sub-tests. These findings follow the logic of construct validity research, as delineated by Cronbach and Meehl (1955), whose study demonstrates a correspondence between a nomological network of relationships between constructs defined by theoretical and empirical studies in literature and the network of empirical correlations found between the observed variables that supposedly measure such constructs. The nomological network was elaborated by the expectations of the relationship between the age and educational constructs with $G f, G c$ and $G v$ found in previous studies. Also previous researches with BRT-5, which justified the most prevalent specific factors in each sub-test, were presented. In the light of this nomological model, the empirical differential relationship of the subtests with age and grade were discussed in respect to their consistency with the expectations elaborated in the nomological network. The results were coherent for some sub-tests, which can support construct validity.

Finally, further studies including psychological tests most clearly associated with $G f, G v, G q$ and $G c$, would be very important in order to corroborate the findings from the present study. This study also suggests different developmental patterns associated with the type of schools. This result is very important and also alarming but the cross-sectional nature of the data for the present research limits the inferences that can be made. Therefore, a longitudinal study would be very important in this regard. Nevertheless, the present study shows the importance of considering this variable when studying intelligence, especially in Brazilian samples.

\section{References}

Ackerman, P. L. (1996). A theory of adult intellectual development: Process, personality, interests and knowledge. Intelligence, 22, 227-257.

Almeida, L. S. (1988). O impacto das experiências educativas na diferenciação cognitiva dos alunos: Análise dos resultados em provas de raciocínio diferencial. Revista Portuguesa de Psicologia, 24, 131-157.

Almeida, L. S., Guisande, M. A., Simões, M. R., Miranda, L. C., Chaves, S., \& Viola, L. (2007). Validade preditiva dos testes de inteligência: Estudos com a Bateria de Provas de Raciocínio. Psychologica, 45, 71-85.

Braun, H., Jenkins, F., \& Grigg, W. (2006). Comparing private schools and public schools using hierarchical linear modeling (NCES 2006-461). Washington, DC: U.S. Government Printing Office.

Cahan, S., \& Cohen, N. (1989). Age versus schooling effects on intelligence development. Child Development, 60, 12381249.

Cahan, S., \& Noyman, A. (2001). The Kaufman Ability Battery for Children Mental Processing Scale: A valid measure of "pure" intelligence? Educational and Psychological Measurement, 61, 827-840.
Carroll, J. B. (1993). Human cognitive abilities: A survey of factor-analytic studies. New York: Cambridge University Press.

Carroll, J. B. (1997). The Three-Stratum Theory of Cognitive Abilities. In D. P. Flanagan, J. L. Gensheft, \& P. L. Harrison (Eds.), Contemporary intellectual assessment: Theories, tests and issues (pp. 122-130). New York: The Guilford Press.

Cattell, R. B. (1963). Theory of fluid and crystallized intelligence: A critical experiment. Journal of Educational Psychology, 54, 1-22.

Cattell, R. B. (1971). Abilities, their structure, growth, and action. Boston: Houghton Mifflin.

Ceci, S. J. (1991). How much does schooling influence general intelligence and its cognitive components? A reassessment of the evidence. Developmental Psychology, 27, 703-722.

Cliffordson, C., \& Gustafsson, J. E. (2008). Effects of age and schooling on intellectual performance: Estimates obtained from analysis of continuous variation in age and length of schooling. Intelligence, 36, 143-152.

Couto, G. (2005). Análise psicométrica da Bateria de Provas de Raciocínio utilizando a Teoria de Resposta ao Item. (Dissertação de Mestrado não-publicada). Universidade São Francisco, Itatiba, SP.

Couto, G. (2007). Desenvolvimento de Escalas com Interpretação Referenciada nos Itens para a Bateria de Provas de Raciocínio. (Tese de Doutorado não-publicada). Universidade São Francisco, Itatiba, SP.

Cronbach, L. J., \& Meehl, P. E. (1955). Construct validity in psychological tests. Psychological Bulletin, 52, 281-302.

Cruz, M. B. Z. (2008). Estudo de Validade e Precisão da Bateria de Prova de Raciocínio Infantil - BPRi. (Dissertação de Mestrado não-publicada). Universidade São Francisco, Itatiba, SP.

Flanagan, D. P., Genshaft, J. L., \& Harrison, P. L. (1997). Contemporary intellectual assessment: Theories, tests and issues. New York: Guilford.

Flanagan, D. P., \& Ortiz, S. O. (2001). Essential of cross-battery assessment. New York: John Wiley \& Sons.

Gustafsson, J. E. (2001). Schooling and intelligence: Effects of track of study on level and profile of cognitive abilities. International Education Journal, 2, 166-186.

Horn, J. L. (1991). Measurement of intellectual capabilities: A review of theory. In K. S. McGrew, J. K. Werder, \& R. W. Woodcock (Eds.), WJ-R technical manual (pp. 197-232). Chicago: Riverside.

Horn, J. L., \& Cattell, R. B. (1966). Refinement and test of the theory of fluid and crystallized general intelligences. Journal of Educational Psychology, 57, 253-270.

Horn, J. L., \& Noll, J. (1997). Human cognitive capabilities. Gf-Gc theory. In D. P. Flanagan, J. L. Genshaft, \& P. L. Harrison (Eds.), Contemporary intellectual assessment: Theories, tests, and issues (pp. 53-93). New York: Guilford.

Johnson, W., \& Bouchard, T. J., Jr. (2005). The structure of human intellect: It is verbal, perceptual and image rotation (VPR), not fluid and crystallized. Intelligence, 33, 393-416.

Kvist, A. V., \& Gustafsson, J. E. (2008). The relation between fluid intelligence and general factor as a function of cultural background: A test of Cattell's investment theory. Intelligence, $36,422-436$

Lemos, G., Almeida, L. S., Guisande, M. A., \& Primi, R. (2008). Inteligência e rendimento escolar: Análise da sua associação ao longo da escolaridade. Revista Portuguesa de Educação, 21, 83-99. 
McGrew, K. S. (1997). Analysis of the major intelligence batteries according to a proposed comprehensive Gf-Gc framework. In D. P. Flanagan, J. L. Gensheft, \& P. L. Harrison (Eds.), Contemporary intellectual assessment: Theories, tests, and issues (pp. 151-179). New York: The Guilford Press.

McGrew, K. S. (1999). The measurement of reading achievement by different individually administered standardized reading tests: Apples and apples, or apples and oranges? (IAP Research Report No. 1). St. Cloud, MN. Institute for Applied Psychometrics.

McGrew, K. S. (2005). The Cattell-Horn-Carroll theory of cognitive abilities: Past, present and future. In D. P. Flanagan, J. L. Genshaft, \& P. L. Harrison (Eds.), Contemporary intellectual assessment: Theories, tests and issues $\left(2^{\text {nd }}\right.$ ed., pp. 136-181). New York: Guilford.

McGrew, K. S. (2009). CHC theory and the human cognitive abilities project: Standing on the shoulders of the giants of psychometric intelligence research. Intelligence, 37, 1-10.

McGrew, K. S., \& Evans, J. J. (2002). Within-CHC domain comparisons of the WJ III Cognitive and Achievement Test growth curves (IAP Research Report No. 7). St. Cloud, MN. Institute for Applied Psychometrics.

McGrew, K. S., \& Flanagan, D. P. (1998). The intelligence test desk reference (ITDR): Gf-Gc cross battery assessment. Boston: Allyn and Bacon.

Phelps, L., McGrew, K., Knopik, S. N., \& Ford, L. (2005). The general (g), broad and narrow $\mathrm{CHC}$ stratum characteristics of the WJ III and WISC-III Tests: A confirmatory cross-battery investigation. School Psychology Quarterly, 20, 66-88.

Primi, R., \& Almeida, L. S. (1998). Bateria de Provas de Raciocínio (BPR-5): Manual técnico. São Paulo, SP: Casa do Psicólogo.

Primi, R., \& Almeida, L. S. (2000). Estudo de Validação da Bateria de Provas de Raciocínio (BPR-5). Psicologia: Teoria e Pesquisa, 16, 165-173.

Primi, R., \& Almeida, L. S. (2002). Inteligência geral ou fluida: Desenvolvimentos recentes na sua concepção. Sobredotação, 3, 127-144.

Sirin, S. R. (2005). Socioconomic status and academic achievement: A meta-analytic review of research. Review of Educational Research, 75, 417-453.

Spearman, C. (1927). The abilities of man: Their nature and measurement. New York: Macmillan.

Stankov, L. (2000a). The theory of fluid and crystallized intelligence: New findings and recent developments. Learning and Individual Differences, 12, 1-3.

Stankov, L. (2000b). Structural extensions of a hierarchical view on human cognitive abilities. Learning and Individual Differences, 12, 35-51.

Stelzl, I., Merz, F., Eulers, T., \& Remer, H. (1995). The effect of schooling on the development of fluid and crystallized intelligence: A quasi-experimental study. Intelligence, 21, 279-296. 